\title{
Research of management subsystems for the development of organizational capital of management companies
}

\author{
Arthur Alukhanyan ${ }^{1, *}$, Natalya Osadchaya ${ }^{1}$, Olga Panfilova ${ }^{1}$ \\ ${ }^{1}$ Don State Technical University, 1, Gagarina sq., 344010, Rostov-on-Don, Russia
}

\begin{abstract}
The article examines the issues of managing the organizational capital of integrated financial groups in the context of financial globalization. It is noted that integrated financial groups at the present stage of their development are faced with the urgent need to invest in improving the skills of employees of management companies to reduce risks and improve their financial stability. The hypothesis about the impact of a decrease in the capital intensity of production on the growth of the market price of shares is substantiated. The urgency of solving these and other problems is determined by the urgent need to implement a competency-based approach to the business development of management companies.
\end{abstract}

\section{Introduction}

One of the main problems in the field of modern economic science is the problem of finding and implementing effective financial management tools that contribute to the growth of the capitalization of multinational companies. At the same time, situatedness and spatiality of Finance are important for understanding financial risks at the individual, institutional and system levels. (1) covers these and other issues related to the perception and management of financial risks within global financial networks. The financial performance of transnational corporations is affected by the economic crisis. The study conducted in (2) showed that aggressive actions of firms (strategic change of the region where products are sold and/or services are provided) can significantly reduce the negative consequences of the crisis. Several studies by foreign and domestic authors raise questions about the impact of corporate social responsibility on the development of a reference strategy for the development of management companies. For example, (3) explores the mechanism of economic value formation through social value.

Another important aspect of managing the growth of the financial capitalization of an integrated financial group is the competence level of the company's personnel (4) sets out the main prerequisites and directions for the formation of an adaptive system for retraining the company's personnel as a factor in ensuring its financial stability.

The company's financial strategy includes elements related, among other things, to planning the optimal capital structure, which is significantly influenced by the use of

*Corresponding: aaalukhanyan78@mail.ru 
various financing instruments. Research paper (5) considers automated trading systems that allow you to predict the number and price of shares as one of these tools. Cash flows of financial corporations are largely determined by investment and financial trends. The research $(6,7)$ attempts to develop innovative technologies to reduce the risk of investment projects.

Despite all the variety of different approaches to managing the development of organizational capital of transnational corporations proposed by foreign and domestic authors, this problem is still insufficiently studied and requires the search and implementation of innovative effective methods and tools for such management. In this paper, an attempt is made to identify and justify the main directions of forming a subsystem for managing the development of organizational capital of management companies.

\section{Materials and Methods}

Management companies are combined financial groups, the core of which is formed by commercial banks. As part of the study of the structure and components of the organizational capital of such companies, various types of risks, information resources, employees, quality indicators of financial products, and strategies for the development of banking structures are subject to mandatory assessment. For this purpose, both General scientific and private scientific methods that are specific to the considered subsystem can be used. This specificity is manifested in the fact that each element of the organizational capital subsystem of a financial company requires the use of specific methods and techniques for its research. For example, methods for analyzing financial stability, creditworthiness, liquidity, and capital adequacy are used to study the financial management system [1].

A financial Corporation is a complex system with many problems arising in its various functional subsystems, including, among other things, the distribution of financial resources, the financial and technological chain, etc. The solution to these problems is possible only through the application of a systematic approach. [1,2]

The existing economic hierarchy of States is based on a mechanism related to various disparities, both price and financial. Access to money and information is a determining factor in the world economy of the twenty-first century. At the end of the XX century, there was a global transformation of world Finance at the level of their qualitative functions. The consequence of this is that the irrationality factor has increased its influence in the global economic space. The growth of virtual finance has led to the expansion of the structure of geofinancial flows.

Among the many strategies of management companies, we can distinguish those that are aimed at increasing their value. [3] Such strategies are in the interests of the entire society. To increase profits, management companies reduce costs, introduce innovative risk assessment and reduction technologies, and new products. [4] Moreover, high profits of management companies attract new competitors to this market segment, which has a beneficial effect on the financial business as a whole, and, consequently, on the level of customer satisfaction.

The global financial market is characterized by a close relationship between the three most important components of an integrated financial group: the image of a financial company, its ability to meet the interests of its team and to the market capitalization of the company's value. The value of a business is influenced by the level of intellectual capital development. Thus, quality management determines the Bank's growth potential.

Professional employment of managers in a successful financial company allows them to develop, expand their skills, and increase personal income, while the success of a modern company is largely due to the presence of highly qualified and motivated employees. [4] 
The value of an integrated financial group's financial asset depends entirely on its ability to generate cash flow. You also need to pay attention to how the cash flow is distributed over time, keeping in mind that the rapid payback of cash injections allows you to reinvest funds, which, in turn, will allow you to count on additional profits. An important characteristic of any financial asset (for example, a stock) is the degree of riskiness of the cash flow generated by it. Therefore, risk-averse investors often prefer less risky stocks. The Russian banking business, at the initial stages of its development, is characterized by a situation when it was creating its own management companies financed by banking structures. Insurance companies were also often created. This was the basis for the emergence of financial groups. The objective of corporate management was to increase the market value of shares by implementing the scale effect of cash flows and turnover, as well as reducing risk. [5]

We can identify the main factors that affect the size of the financial capital of management companies. This is primarily the turnover of financial products; operating profit remaining at the company's disposal after-tax; and advanced capital.

The volume of sales of financial products depends on the current level of demand for the corresponding product and the forecast value of its growth rate. Increasing cash flows is possible only when a financial company adequately accepts the needs of its customers and offers high-quality financial products.

The increase in the financial capital of the management company is also significantly affected by the amount of operating profit that remains at the disposal of the company after taxes are paid. The company's management may decide to increase the prices of financial products to increase the operating profit index, but the use of this method to influence profits may be significantly limited by the effective demand of potential customers for financial products and services. Developed financial markets provide for the possibility of setting a price that exceeds the price of similar products of competitors only if the corresponding financial product or service meets the needs of customers better than the products of competitors. As a rule, such financial products include consulting services and risk management.

In the context of financial globalization, reducing direct costs is no longer seen as a way to increase profits. Management companies can effectively carry out their activities by increasing payroll and spending more money on research in the field of risk assessment. Determining factors when choosing a financial operator from an expensive market segment is the company's financial stability and the level of its risk management.

Integrated financial groups in modern conditions are faced with the need to spend money on improving the skills of their employees and their retraining. These measures have a significant impact on the level of competitiveness of the financial company's human capital.

The creation of cash flows is preceded by investments, so organizational capital is one of the factors that affect the size of the financial capital of the management company. As a rule, organizational capital is directed to investments in buildings and structures, equipment, and the development of information and marketing communications. When investing in fixed and working capital, there is a situation when managers of financial company rent buildings, cars, and inventory items from investors, and are required to pay interest in using them. Thus, a decrease in the capital intensity of production can potentially affect the increase in cash flows and the share price.

When deciding on the company's financial strategy, managers plan the optimal capital structure and financing instruments, which, in particular, may include securities. At the same time, the financial stability of the management company is achieved, among other things, by determining the part of net profit that will be used to optimize the structure of financial capital sources, pay dividends to shareholders and reinvest.

Cash flows of a financial Corporation (figure) are characterized by their level, time 
reference to calculation steps, and risk indicators. [6] These components of cash flows, and therefore the market prices of corporate securities, are influenced by investment and financial trends. Thus, achieving the competitiveness of integrated financial groups is impossible without implementing a strategy to maximize the Corporation's shareholder value.

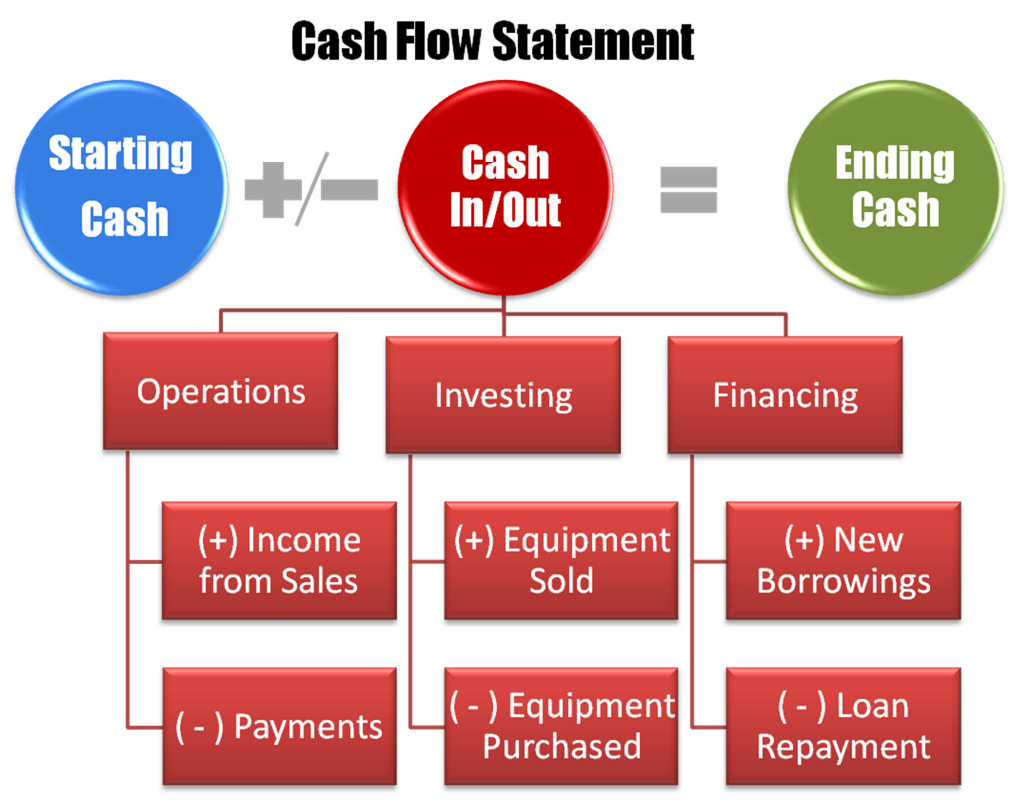

Fig. 1. Cash flow statement.

External factors of the management company's environment also have a significant impact on its cost. Legal restrictions, the overall level of business activity, the tax environment, interest rates, and the balance of the stock market have the greatest impact on the market capitalization of a Financial Corporation. One of the main tasks of modern management is to plan a long-term strategy for the development of a Financial Corporation. Such strategies, in many ways, determine the cash flows expected in the future. The share price is affected by a combination of these factors, as well as the General stock market environment.

The main goal of the development strategy of financial companies is to enrich shareholders. In the process of evaluating the activities of a financial Corporation, a value generation strategy is modelled. The new economy reflects the so-called balanced scorecard (BSC), introduced by American economists Robert S. Kaplan and David P. Norton in 1996. This indicator is used by corporations to evaluate their intangible assets. "The structure of the BSC includes financial activities, interaction with target customers, and reengineering of internal business processes based on competitive intangible assets (human, information, and organizational capital)."

One of the features of network corporations is that in the context of globalization, intangible assets are the main source of value formation for them. A prerequisite for creating value is the presence of an effective business process in the internal environment of the Corporation. An effective business process is built based on an institutional and network development strategy for strategic professional groups, a strategic information technology portfolio, an organizational change plan, and strategic marketing. The globalization of the economy contributes to significant changes occurring within the framework of systemic events. A financial company can detect such systemic events that 
are key to determining the mechanism for developing a long-term strategy for the development of such a company.

Management companies are subject to transformation, which is affected by system events. As mentioned above, one of the priority tasks facing the management of a financial company is to identify such systemic events. To do this, you can use the General scheme of the system development process developed by Professor V. D. Mogilevsky. The system appears from an unorganized unstructured environment, while the environment is homogeneous, amorphous, stable, "information state estimates correspond to the maximum entropy" (Homogeneous medium - system - the medium is homogeneous in composition, its properties are the same in all parts, if they change, then continuously (smoothly), without jumps.

Entropy is a measure of the system's internal disorder. In closed systems, all processes that occur are accompanied by an increase in entropy (the process is irreversible), and preservation of the entropy level (the process is reversible). The maximum level of entropy means the highest degree of disorganization, in which any external influences are not perceived, and quickly fade away, which confirms the "weak sensitivity of the environment to the action of disturbances").

When space is systematized, a homogeneous mass is transformed into a state in which each element of the mass is designed to perform its specific function. Thus, the homogeneous mass acquires a non-uniform, multi-level character. Each part of such a heterogeneous mass develops or fades away depending on the relevance of the function for which it is intended. The environment, in its original state, can be characterized using "stable deterministic estimates of probabilistic description". The stability of the system is ensured by global equilibrium. There are two cases of violation of the global equilibrium of systems.

The first option is associated with a "powerful" external influence, the destruction of some "fatal" order in certain locations of the system. In such points of the system, order (equilibrium) is artificially established, and local stability created in separate "zones" is maintained. "Chaos is structured, zones with a stable state of components appear, which ensures the appearance of structured units."

In the second case, the self-organization of systems takes place. Here the mechanism connected with transformation, the transformation of parts of the environment comes into action. As a rule, this mechanism is based on irreversible processes. The structuring of the system is being developed, and quantitative growth and qualitative changes are taking place in the newly created stable structures. This is manifested in an increase in the number of parts of structures, the acquisition of new properties by these parts, and their functional modification. As a result of such qualitative transformations, the system may be subject to a bifurcation.

When the structure has not yet developed, the connections between the parts of the system have not been strengthened, the structure is characterized as mobile, and both positive and negative changes in the system can be observed. When the system structure is formed, its elements are simultaneously specialized. At the same time, the elements of the system get a stable functional purpose. The type of system changes, it acquires new qualitative properties, which ultimately leads to an increase in its viability.

The financial system evolves and goes through successive steps of development within its life cycle. Each intermediate step is replaced by the next stage in the development of the system. Thus, we can say that at the end of the intermediate stage, the process of appearance of the system of the next hierarchical level begins. The relationship between the processes of system evolution and the emergence of new systems at the next levels of the hierarchy can be determined through the prism of the following conditions:

- quantitative and qualitative changes in the systems of the previous level of the 
hierarchy, which will be absorbed by the new system of a higher level and will form parts of it after the transformations;

- the nascent system appears as an external environment for the development of systems of the previous level of the hierarchy.

The economic space covered by the newly formed system is characterized initially by a state of equilibrium, the violation of which may be associated with various situations arising from the General scheme of the evolution of systems. As one of the possible variants of such changes, the appearance of structural formations that were not previously characteristic of this system is highlighted. This happens as a result of self-organization that takes place in this economic space. Another option is related to the fact that local formations may appear as the result of volitional decisions. Both options can be implemented simultaneously. The emergence of a new system is based on the previous steps of development, in changes in the economic space.

It should be noted that a new vital system takes root in the global space when its generalized characteristics (information, energy) reach their minimum. The information minimum indicates a high degree of ordering of relations, while the energy minimum indicates the stability of the newly born formation.

This shows some certainty of qualitative and quantitative criteria, the development of which is necessary to identify the moment of achievement of critical indicators that characterize the limiting States of the global system throughout its life cycle, to assess the direction of improvement of the system, as well as its consolidation.

Evidence that the system has already outlived its usefulness and there is an urgent need for its rebirth in the system of the next hierarchical level is the exit of the global system from a stable state. The nature of the instability of the system, as a rule, is due to the impossibility of its further development, provided that the qualitative and quantitative properties of the system are preserved.

The globalization of the world economy has several significant implications for the development of integrated financial groups. They are manifested, first of all, in changes in the structure of interest groups in modern Russian business, as well as the vector of determining commercially and economically verified strategies for the development of the Corporation. An effective search for the future development vector of a management company is based on an important rule: changing the vector must be preceded by an understanding that the potential of the old course of development has been exhausted.

In General, the investment and the financial sector is subordinate to operating (production) activities. We can talk about the infrastructure of this phenomenon. Moreover, when it comes to such an organizational form of entrepreneurial activity as a financialindustrial group (FIG), consortium, conglomerate, etc., the banking sector acquires not the infrastructure (subordinate, auxiliary), but the main (determining) character.

In the global space, there is an economic paradox, which consists in the fact that management companies (financial groups), being financial levers, are mistakenly perceived as a resource base for the organization of business activities. At the same time, financial institutions are designed only to ensure the normal functioning of Finance, which is nothing more than a reflection of economic resources in monetary form, in the global economic space. $[7,8]$

For the banking sector of the economy, it is characteristic that the category of value is manifested here through abstract media. This means that it is impossible to equalize the financial and production spheres of economic activity with each other, which contradicts one of the essential principles of the system's functioning - the principle of its qualitative definition. The reason for this methodological error is the dominance of the financial component in the structure of group interests characteristic of the Russian economy. [9, 10]

The realities of the global world economy today are such that it is very difficult, if not 
impossible, to forecast changes in the banking sector and to model promising strategies for the development of financial institutions. The financial system, especially in the period of globalization, is subject to destructive processes, which are expressed in the increased propensity of the system to self-destruction, which can be caused by various financial and economic crises. The end of the bifurcation phase should be marked either by the onset of a new stage of development, the rebirth of the system, or the destruction of the financial system.

One of the reasons for the destruction of the system can be a situation in which the system loses its stability. This can be caused by both external and internal processes. The second reason is usually related to structural problems in which there is a violation of internal links between elements of the system. As a result, the financial system is going through a process of changing the conditions surrounding it, which logically leads to changes in the internal parameters of the system's functioning, which are reflected in the General vector of its development.

International financial organizations and transnational financial and credit institutions support the processes of globalization, which provide for the rejection of the financial borders of States, changing the economic structural policy of developing countries in the direction of developing innovative industries. The result of globalization processes is, in the end, the increasing dependence of national economies on international organizations and financial institutions, and then their final destruction.

In this regard, there is an urgent need to develop and implement a mechanism for creating and developing infrastructure for transferring national economies to new innovative tracks, which imply innovative technologies and mechanisms of globalization. The emergence of this mechanism has led to the fact that the processes of globalization have taken a slightly different form and have become characterized by different dynamics.

The processes of globalization, affecting the business of corporate structures, lead to the building of certain connections in the internal environment of such structures. If the corporate business management model is dominated by vertical relationships, then the model is characterized as administrative, and the relationships are called rigid. In the case of a corporate structure based on horizontal links, the management model is market-based, and the links can be described as flexible. The exchange of goods and services in market conditions is always equivalent if we start from a subjective basis. On the contrary, in the case of an objective basis, it is nonequivalent. The peculiarity of the network economy is that it is moving from vertical economic relations, characterized by subject-object relations, to horizontal relations, which are characterized by relations between different subjects. The system paradigm focuses on processes related to the development and transformation of system institutions and events.

Corporate shareholders tend to get high returns on their investments while avoiding unnecessarily high risks. The Corporation's management system is designed in such a way that shareholders approve top management, which, in turn, is engaged in the selection of managers who perform operational management of the company. Thus, we can say that corporate governance is carried out on behalf of shareholders and in the name of their interests.

The main task of managers is to increase the welfare of shareholders, which means the maximum increase in the market price of ordinary shares of the company. The cost of any enterprise increases significantly when it is reorganized into a Corporation.

The growth of pension funds [11], life insurance companies, and mutual funds $[12,13]$ in the second half of the twentieth century in the countries of the centre led to the redistribution of financial capital. Currently, these institutions collectively own more than $60 \%$ of all US shares. Also, more than $43 \%$ of US adults own shares individually, compared to only $22 \%$ of shareholders in the country in 1990 . Most of the citizens of 
developed countries have pension plans, receiving indirect income from holding sharesthrough the growth of their pension savings, therefore, they are interested in the growth of the corporate share price.

Financial management indicators, and especially the main one-profit, are calculated based on more or less standardized accounting methods, and it is assumed that net profit reflects the firm's potential to create cash flows over time. [14] However, there are significant differences between profit and cash flows.

Although the value of a firm to shareholders is determined by its cash flows, financial managers should use an indicator in their annual reports that determines the ratio of earnings per share, since profit announcements always serve as information for investors. When deciding to restructure the business, which will significantly increase future cash flows and thus raise the firm's share prices, it should be understood that the short-term effect of the transformation will be a decrease in earnings per share.

Such a solution may be to change the inventory accounting policy, which increases the declared value of products sold, reduces revenues, but increases cash flows due to tax cuts. In this case, it is likely that instead of a rise in the share price, there will be a fall - due to the effect of a negative signal caused by a drop in earnings per share.

When financial management was finally established as a separate field of science at the beginning of the XX century, the main focus was primarily on the legal aspects of taxation and mergers of companies, the formation of new firms, and the various types of securities that firms could issue to attract capital. During the great depression of the twentieth century, the focus shifted to bankruptcy and reorganization, corporate liquidity, and securities market regulation. During the $40 \mathrm{~s}$ and early $50 \mathrm{~s}$, financial management was primarily focused on financial analysis. However, at the end of the $70 \mathrm{~s}$, when financial globalization began to develop, there was a movement towards theoretical analysis, and the focus shifted to managers' solutions developed to increase the shareholder value of corporations.

The focus of financial management on maximizing business value in the era of globalization has changed the concept of financial analysis, highlighting the following new areas as priorities:

1) the globalization of business;

2) use of information technologies;

3) the level of development of the network.

These trends provide companies with new opportunities to improve the profitability of financial management and reduce risks, but they also lead to increased competition and the emergence of new, previously unknown sources of risk.

\section{Conclusion}

If the main characteristic of globalization is the interdependent development of two processes: the globalization of markets (capital, labour, goods and services) and the globalization of economic forms (consolidation of organizational structures of the economy, the formation of global players) [15], then the combination of these processes is an essential characteristic of globalization trends in the financial market. The transnationalization of banking services means the development of the stage of economic globalization in the financial services market, which gradually acquired modern forms of manifestation: information and communication, and financial and organizational.

Transnational management companies and integrated business groups form and implement competency-based approaches to business development and exist as product chains focused on manufacturers and product chains focused on consumers.

The guarantee of success of the management strategy in such a structure is the 
positioning of the company (or a specific production project) within the network to obtain a competitive advantage for this particular position in the market for management companies.

\section{Acknowledgement}

The research was carried out with the financial support of the RFBR in the framework of the scientific project No. 19-010-00904.

\section{References}

1. E. Svetlova, K. Thielmann, Financial Risks and Management, International Encyclopedia of Human Geography (Second Edition) (2020)

2. X. Zhao, X. Jiang, Z. Li, International Review of Economics \& Finance 37, 55 (2015)

3. M. Ligonie, Long Range Planning 51, 463 (2018)

4. N.G. Vovchenko, A.A. Alukhanyan, L.Yu. Andreeva, G.A. Buryakov, European Research Studies Journal 21, 3 (2018)

5. G. Jeong, H.Y. Kim, Expert Systems with Applications 117, 125 (2019)

6. A.S. Orobinsky, A.A. Alukhanyan, R.A. Sychev, M.G. Kholina, European Research Studies Journal 21, 333 (2018)

7. P. Luukka, M. Collan, Insurance: Mathematics and Economics 65, 22 (2015)

8. Chi-Chuan Lee, Chien-Chiang Lee, Yan-Yu Chiou, Journal of International Financial Markets, Institutions and Money 51, 155 (2017)

9. I. Ablaev, Procedia Economics and Finance 5, 4 (2013)

10. A. Abramov, A. Radygin, M. Chernova, Russian Journal of Economics 3, 1 (2017)

11. M. Alda, International Review of Fynancial Analysis 49, 83 (2017)

12. A.M. D'Arcangelis, G. Rotundo, Journal of Business Research (2019)

13. S. Kucinskas, Journal of Banking \& Finance 101, 1 (2019)

14. L.T. Damonte, A.G. Woodside, Journal of Business Research (2020)

15. P. Sethi, D. Chakrabarti, S. Bhattacharjee, Journal of Policy Modeling (2020) 